\title{
Trigeminal sensory neuropathy and bilateral carpal tunnel syndrome: the initial manifestation of mixed connective tissue disease
}

\author{
F M VINCENT AND R N VAN HOUZEN \\ From the Munson Medical Center, Traverse City, Michigan, USA
}

SUMmARY A patient is described who developed a bilateral carpal tunnel syndrome and a trigeminal sensory neuropathy as the initial manifestations of mixed connective tissue disease. Either condition can occur in other connective tissue diseases, but this combination has not been reported previously in mixed connective tissue disease, in which, however, trigeminal sensory neuropathy is frequently seen.

Involvement of the sensory portion of the trigeminal nerve occurs in various disorders. "Primary" idiopathic sensory involvement is not associated with other neurological or systemic disorders, whereas "secondary" involvement is seen with tumours, connective tissue diseases, demyelinating disorders, trauma, or secondary to toxic substances. ${ }^{1}$ Likewise, the causes of the carpal tunnel syndrome are many and varied; any condition causing an increase of mass in the carpal tunnel can cause compression of the median nerve.

A recently described connective tissue disease, mixed connective tissue disease, consists of overlapping features of progressive systemic sclerosis, lupus erythematosus, and polymyositis. ${ }^{23}$ The syndrome is characterised by the presence in the serum of an antibody which is specific for extractable nuclear antigen; serum from patients with mixed connective tissue disease have high titre antibody to extractable nuclear antigen and ribonucleoprotein; in contrast, patients with lupus erythematosus may have normal extractable nuclear antigen titres, but have elevated titres of antibody to $\mathrm{Sm}$ antigen. ${ }^{2}$

We report the case of a patient who presented with bilateral carpal tunnel syndromes and trigeminal sensory neuropathy as the initial manifestations of mixed connective tissue disease.

Address for reprint requests: Dr FM Vincent, 211 Beaumont Place, Traverse City, Michigan 49684, USA.

Accepted 10 February 1980

\section{Case report}

A 52 year old male, employed as a grinder in an iron works, complained of numbness and paresthesias in both hands. He soon developed aching in his neck and proximal upper extremities, and numbness which started in the maxillary area on the right, but which in one week involved the entire right side of his face. $\mathrm{He}$ also complained of swelling of the hands with tightness of the skin, without arthralgia or Raynaud's phenomenon. His past history was unremarkable, except for pneumoconiosis (silicosis) related to his occupational exposure to grinding dust.

General physical examination was unremarkable, except for the presence of diffuse inspiratory rales and swelling and induration over the fingers, and to a lesser extent over the hands. Neurological examination revealed that the corneal reflex on the right side was diminished (afferent), as was pin and light touch sensation over the entire trigeminal nerve distribution as far as the vertex of the skull. Hypaesthesia was present on the buccal mucosa, and on the anterior two-thirds of the tongue on the right. Tinels sign was present at both wrists over the median nerves, but there was no Phalens sign. There was no weakness or sensory loss, and muscle stretch reflexes were all present. The remainder of the neurological examination was normal.

Laboratory examinations revealed a haemoglobin of $14.6 \mathrm{~g} / \mathrm{dl}$ and a haematocrit of $44 \%$. Erythrocyte sedimentation rate was $33 \mathrm{~mm} / \mathrm{hr}$ (normal 0-20), 
creatinine phosphokinase $178 \mathrm{IU} / \mathrm{L}$ (normal 30-170), aldolase $16 \mathrm{IU}$ (normal up to $7 \cdot 5$ ), serum glutamic oxaloacetic transaminase $69 \mathrm{IU} / \mathrm{L}$ (normal 8-30), and lactic dehydrogenase $402 \mathrm{IU} / \mathrm{L}$ (normal 90-210). A urinary heavy metal and porphyrin assay were negative. Serum protein electrophoresis revealed a polyclonal gammopathy with a total protein of $7 \cdot 5 \mathrm{~g}$, albumin $4.0 \mathrm{~g}$, and gamma globulin $1.9 \mathrm{~g}$. Rheumatoid factor was positive at a titre of $1: 40$, and antinuclear antibody was present in a titre of 1:160 with a speckled pattern. Ribonucleoprotein was positive, and $\mathrm{Sm}$ antibodies were negative. Extractable nuclear antigen was present in a titre of $1: 12500$ (normal is less than $1: 1000$ ). Base views of the skull and barium swallow examination were normal. A chest roentgenogram showed evidence of bilateral silicosis.

Nerve conduction studies revealed the following: both median nerve sensory action potentials were absent; the right median motor conduction velocity was $56 \mathrm{~m} / \mathrm{s}$, with a distal latency of $5.7 \mathrm{~ms}$; the left median motor conduction velocity was $51 \mathrm{~m} / \mathrm{s}$, with a distal latency of $6.1 \mathrm{~ms}$; ulnar nerve conduction velocities and distal latencies were normal bilaterally. Electromyographic examination revealed the presence of increased insertional activity, positive sharp waves, and fibrillation potentials in the proximal upper extremities, together with myopathic potentials on volition. A skin biopsy from the right index finger showed features consistent with scleroderma.

The patient was treated with prednisone $60 \mathrm{mg}$ daily, and although the sensory symptoms in his hands resolved, the facial numbness was unchanged.

\section{Discussion}

Mixed connective tissue disease was first described by Sharp et $a l^{2}$ as an overlap syndrome of systemic lupus erythematosus, progressive systemic sclerosis, and polymyositis. The initial impression has been that mixed connective tissue disease tends to be more of a benign connective tissue disease, especially when the nervous system is involved ${ }^{3}$. The patient described here had features consistent with systemic sclerosis (scleroderma), elevated muscle enzyme levels and a electromyographic examination consistent with polymyositis, together with a high serum titre of extractable nuclear antigen; thus, the diagnosis of mixed connective tissue disease fits best.

Carpal tunnel syndrome occurs in many diseases causing synovitis at the wrist, and has been seen as the first manifestation of such diseases as lupus erythematosus and systemic sclerosis, but we have been unable to find any reports of it occurring as the initial manifestation of mixed connective tissue disease, although it would not be an unexpected finding.

Trigeminal neuropathy, usually purely sensory, rarely has been reported to accompany connective diseases. Ashworth and Tait $^{4}$ reported six patients who developed facial numbness: three had systemic sclerosis, two had systemic lupus erythematosus with features of systemic sclerosis, and one had polymyositis. All complained of numbness in the face, and pain was a feature in some. In three patients neuropathy was bilateral. It is possible that the patients with systemic lupus erythematosus with features of systemic sclerosis would be defined today as having mixed connective tissue disease. In all these patients the area of involvement remained quite constant for a number of years and did not respond to treatment.

Bennett et $a l^{3}$ reviewed the neuropsychiatric manifestations of mixed connective tissue disease. Of their 11 patients, two had trigeminal neuropathy, unresponsive to treatment. Aseptic meningitis occurred in four patients, convulsions in two and peripheral neuropathy in two. The patients with the aseptic meningitis-like illness and one of the patients with convulsions responded favourably to corticosteroid medication. These authors found a $55 \%$ incidence of neuropsychiatric problems in their patients with mixed connective tissue disease, but such nervous system involvement was not associated with any mortality, as has been the case with systemic lupus erythematosus.

Trigeminal sensory neuropathy is not purely confined to connective tissue diseases. Facial numbness may be the initial symptom of disease of the nervous system, and although it is uncommon, it is not rare. ${ }^{1}$ Horowitz ${ }^{1}$ reviewed 64 patients with facial numbness as an initial or presenting symptom. Fifty-three patients had trigeminal involvement secondary to other conditions: 27 had tumours of the cerebellopontine angle of base of the skull, two had intramedullary tumors, five had multiple sclerosis, six had multiple cranial nerve palsies on a viral basis, three had dental or facial trauma, and two had vascular diseases. In seven patients $(11.7 \%)$ no underlying disease was found.

The cause of trigeminal neuropathy in mixed connective disease is unknown. Because patients with connective tissue can develop peripheral nerve dysfunction, including mixed motor-sensory neuropathy, sensory neuropathy or mononeuritis multiplex, a vasculitis involving the gasserian ganglion is a possibility. Perhaps in mixed connective tissue disease the trigeminal nerve is more selectively vulnerable than other parts of the nervous system. Immune complex formation in the nerve itself or in the sensory root could possibly cause isolated trigeminal sensory dysfunction. Nerve biopsy from a 
patient with mixed connective tissue disease has shown vasculitis, nerve connective tissue fibrosis, together with nerve infarcts and damage to both axons and myelin. ${ }^{5}$ There have been no autopsy studies reported on patients with mixed connective tissue disease with trigeminal nerve dysfunction, but one case of a fatal transverse myelitis in a patient with mixed connective tissue disease has been reported, ${ }^{6}$ and the spinal cord changes were secondary to vasculitis involving the cord, with multifocal necrosis seen as the end stage of vascular involvement.

Thus, the presence of an isolated trigeminal sensory neuropathy in a symptomatic patient should thoroughly be investigated. Because there may be a long interval between the onset of symptoms and the discovery of the cause of the neuropathy the patient should be examined periodically. However, approximately $10 \%$ of patients with isolated facial numbness will not develop associated neurological or systemic diseases. One should also be aware that the carpal tunnel syndrome may rarely be the presenting manifestation of a connective tissue disease.

We would like to thank Dr Jim Milliken for his help in evaluating our patient, and Ticia Vincent for her preparation of the manuscript.

\section{References}

1 Horowitz SH. Isolated facial numbness: clinical significance and relation to trigeminal neuropathy. Ann Int Med 1974; 80:49-53.

2 Sharp GC, Irvin WS, Tan EM, Gould RG, Holman HR. Mixed connective tissue disease an apparent distinct rheumatic disease syndrome associated with a specific antibody to extractable nuclear antigen (ENA). Am J Med 1972; 52:148-59.

3 Bennett RM, Bong DM, Spargo BH. Neuropsychiatric problems in mixed connective tissue disease. Am J Med 1978; 65:955-62.

4 Ashworth B, Tait GBW. Trigeminal neuropathy in connective tissue diseases. Neurology (Minneap) 1971; $21: 609-14$.

5 Currie DM, Bradshaw DC. Polyneuropathy in mixed connective tissue disease presenting as progressive systemic sclerosis (scleroderma): case report and literature review, abstracted. Arch Phys Med Rehabil 1979; 60:594.

6 Weiss TD, Nelson JS, Woolsey RM, Zuckner J, Baldasarre AR. Transverse myelitis in mixed connective tissue disease. Arthritis Rheum 1978; 21:982-6. 